\title{
Aerodynamic Loads on Lightweight Railway Vehicles for the Evaluation of Rollover Risk
}

\author{
F. Cheli ${ }^{1}$, S. Giappino ${ }^{1}$, G. Tomasini ${ }^{1}$, M. Villani ${ }^{1}$ and G. Zanetti ${ }^{2}$ \\ ${ }^{1}$ Department of Mechanical Engineering \\ Politecnico di Milano, Italy \\ ${ }^{2}$ AnsaldoBreda Costruzioni Ferroviarie, Pistoia, Italy
}

\begin{abstract}
In this paper, the effects of lateral wind on two different light-weight trains, characterised by different geometries and lengths and by different mass distribution, are investigated. In order to compare the two trains in terms of response to cross wind, two subsequent analyses have been performed: measurement of the force aerodynamic coefficients by means of wind tunnel tests on scale models, and evaluation of the rollover risk by means of the definition of the characteristic wind curve (CWC) through a simplified numerical procedure, based on the static equilibrium, proposed by the TSI standard (three mass model).

As expected, the longer train presents the larger aerodynamic coefficients. However, differences on the lateral force coefficient and rolling moment coefficient arise also due to the different geometry of the trains in the upper part of the carbody. Finally, from the CWC evaluation, it has been found that variations between the two trains reduce at low wind angle and at low vehicle speed.
\end{abstract}

Keywords: lightweight railway, crosswind, rollover risk, force aerodynamics coefficients, wind tunnel tests.

\section{Introduction}

High cross-winds on rail vehicles may result in a risk of blowing over that can occur in practice, and in the design of any new train these risks have to be considered very seriously [1,2]. This has led to the development of specific standards to lay out rigorous risk-assessment procedures for vehicles to operate [3,4] on exposed lines. All risk analysis methods require the knowledge of cross-wind aerodynamic force and moment coefficients, that are generally obtained through wind tunnel testing on scaled models $[1,5,6]$.

Even if cross-wind effects are of critical importance in high-speed trains also lightweight railway vehicles can suffer of these problems. 
In this research activity we investigate the effects of lateral wind on two different light-weight trains, in the following named train A and train B. The two vehicles have different layout solutions: train $\mathrm{A}$ is only $13.3 \mathrm{~m}$ long while train $\mathrm{B}$ is $17.5 \mathrm{~m}$ long. In addition, the mass distribution is different.

In order to compare the two trains in terms of response to cross wind, two subsequent analyses have been performed: experimental measurement of the force aerodynamic coefficients and evaluation of the rollover risk by means of a numerical procedure.

Aerodynamic coefficients have been obtained through wind tunnel tests on scaled model of the vehicles (1/15 scaled the train A and 1/20 the train B) carried out in the Politecnico di Milano Wind Tunnel (CIRIVE). The tests have been performed with a flat ground scenario (without ballast and rails), which is one of the reference scenarios described in the TSI 232/2008 standard with a $\operatorname{Re}_{\max }=5.510^{5}$.

Various methods have been developed during these last years to determine the rollover risk: most of them are based on the wheel unloading due to cross-winds. The most common tool used to evaluate the risk of overturning is the calculation of Characteristic Wind Curves (CWC, [4]): for each train speed, the CWC is defined as the limit wind speed causing a vehicle to exceed safety limits such as, for example, wheel unloading. In this research the three mass model method, reported in detail in [3] and based on the quasi-static equilibrium [7] between the mean aerodynamic loads and the weight force, has been applied. Data obtained from this simple method are considered to be less precise with respect to the dynamic methods, as Chinese Hat and Stochastic method $[3,8,9,10]$ but they are conservative and can be used for comparison purposes.

\section{Wind tunnel tests}

Wind tunnel tests on the two considered vehicles were carried out in the Politecnico di Milano Wind Tunnel employing a 1:15 scale model for the train A (Figure 1-a) and a 1:20 scale model for the train B (Figure 2-b). Tests were performed in a highspeed test section $(4 \times 4 \mathrm{~m})$ in low turbulence flow conditions. The test section is characterized by an along-wind turbulence $\left(\mathrm{I}_{u}\right)$ below $0.1 \%$, while the maximum mean velocity deviation across the section is less than $0.2 \%$.

The convoy of the train A is composed by two symmetrical vehicles (Figure 1-a). The convoy of the train B is composed by three vehicles: the first two vehicles are instrumented, while the third one is reproduced only to correctly reproduce the boundary conditions (Figure 1-b).

Table 1 resumes the three main dimensions, length, width and height of the full scale vehicles for both the considered trains.

Tests with both the trains have been carried out on a flat ground scenario (without ballast and rails), which is one of the reference scenarios described in the TSI $232 / 2008$ standard [4]. To realise the flat ground scenario a splitter plate, $350 \mathrm{~mm}$ high, has been adopted in order to have an equivalent block profile of the mean wind speed. 


\begin{tabular}{cccc}
\hline Train/Vehicle & Length & Width & Height \\
\hline A & 13319 & 2648 & 3335 \\
\hline B/first & 17455 & 2650 & 3600 \\
\hline B/second & 16760 & 2650 & 3600 \\
\hline
\end{tabular}

Table 1: Dimensions of the full scale vehicles for both the considered trains (measures in $\mathrm{mm}$ )

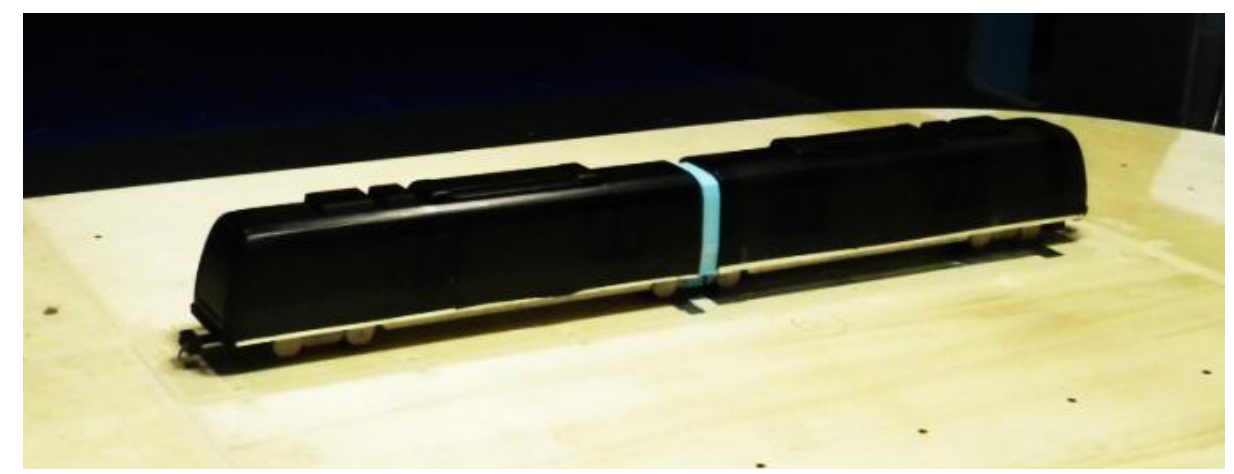

(a)

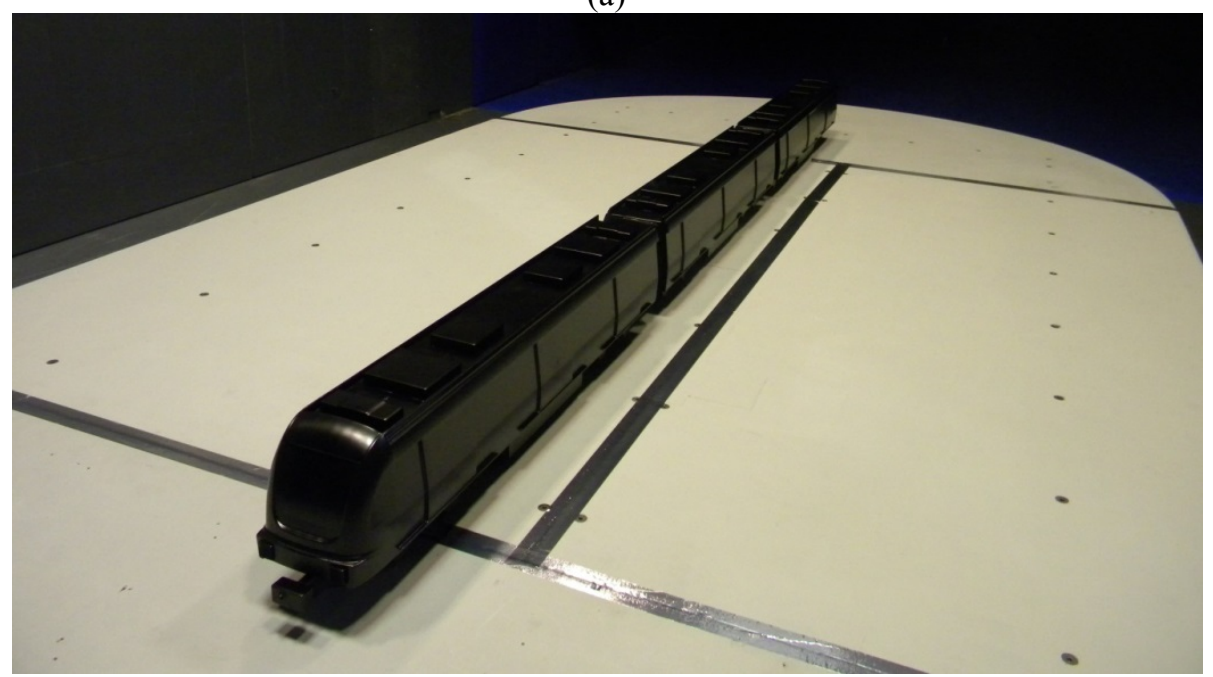

(b)

Figure 1: Models in the wind tunnel test section. 1:15 scaled train A and 1:20 scaled train B

\subsection{Measurement set up}

Given the symmetry of train A, only one vehicle has been instrumented to measure the aerodynamic forces but wind angles have been changed in a range of $180^{\circ}$ so as to measure coefficients for both positions of vehicle, in front or behind. On the other hand, the first and the second vehicles of train B have been contemporary instrumented.

For the train A, a 6-components force balance (RUAG 192) is connected to the model by two stalk threads in correspondence of the boogies (see Figure 2).

For the train B, two force balances are connected to the first two vehicles model by means of steel poles in the center of the underbody. In both the configurations, the 
stiffness of the connection ensures that the aerodynamic forces that arise on all the external surfaces of the vehicle model are transferred only to the dynamometric balance. The figure also shows the reference system of the measured forces: the reference frame adopted for the definition of the aerodynamic forces is fixed to the carbody and its origin is coincident with the carbody centre, at ground level. The wind angle $\beta_{\mathrm{w}}$ with respect to the vehicle is zero when the wind is parallel to the vehicle, opposite to the running direction.

The mean flow velocity for the calculation of the aerodynamic coefficients is evaluated from the measurement of the static differential pressure in two points of the wind tunnel convergent. The sampling rate is equal to $200 \mathrm{~Hz}$.

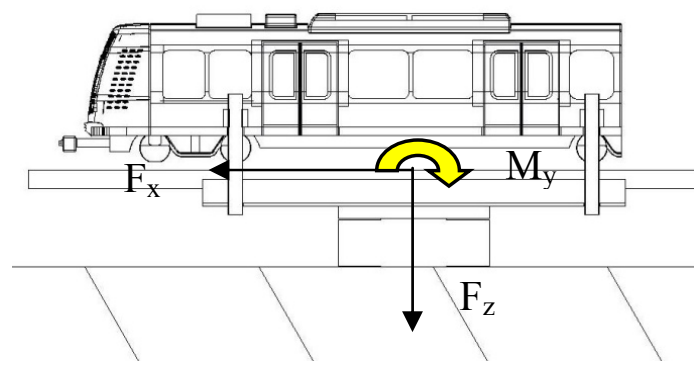

(a)

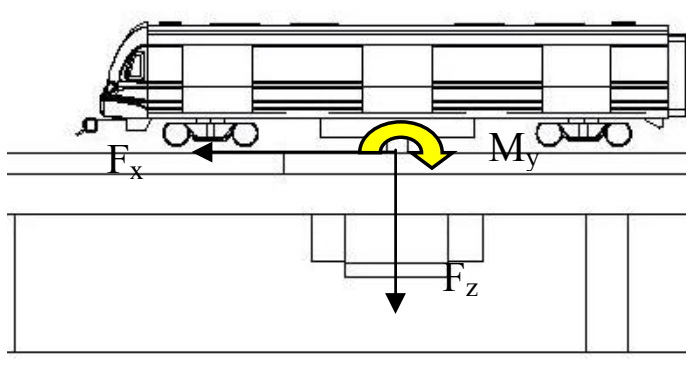

(b)

Figure 2: Connection system between model and balance: train A (a) and train B (b)

\subsection{Aerodynamic force coefficients}

According to the CEN standard [3], the non-dimensional coefficients are defined as follows:

$$
\begin{aligned}
C_{F_{i}} & =\frac{F_{i}}{1 / 2 \rho A \bar{U}^{2}} \\
C_{M_{i}} & =\frac{M_{i}}{1 / 2 \rho A h \bar{U}^{2}}
\end{aligned}
$$

where $\mathrm{F}_{\mathrm{i}}(\mathrm{i}=\mathrm{x}, \mathrm{y}, \mathrm{z})$ are the aerodynamic force components in the train's reference system and $\mathrm{M}_{\mathrm{i}}(\mathrm{i}=\mathrm{x}, \mathrm{y}, \mathrm{z})$ are the corresponding moments. In equation $1, \rho$ is the air density, $\bar{U}^{2}$ is the mean square value of the wind speed, $h$ is equal to $3 \mathrm{~m}$ (full scale), and $A$ is a standard reference surface which is equal to $10 \mathrm{~m}^{2}$ (full scale).

All the coefficients are evaluated on the midpoint of the track at top of the rail (see Figure 2), while the rolling moment is calculated both with respect to the middle of the track $\left(\mathrm{CMx}_{\mathrm{M}}\right)$ and with respect to the lee rail $\left(\mathrm{CMx}_{\mathrm{M}}\right.$ lee). 


\section{Experimentation results}

Figure 3 shows the force coefficients most significant for the cross wind problem measured on the first vehicles of convoys both. It is possible to observe that the lateral force and the rolling moment coefficients (Figure 3-a and Figure 3-c respectively) of train $A$ are significant lower than the corresponding coefficients of train $\mathrm{B}$ at all yaw angles.

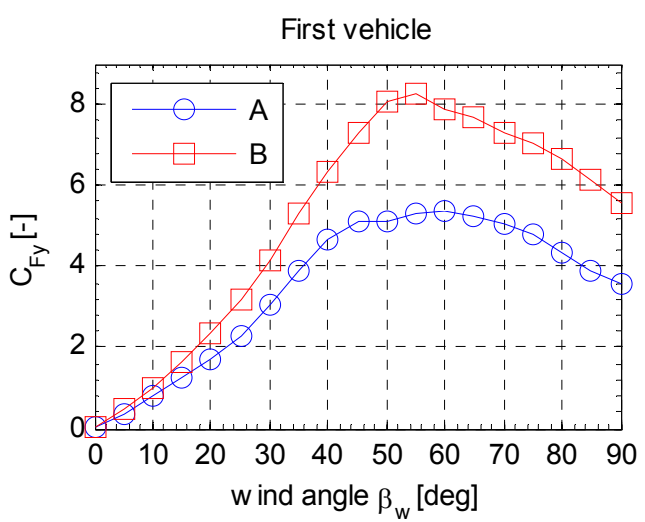

(a)

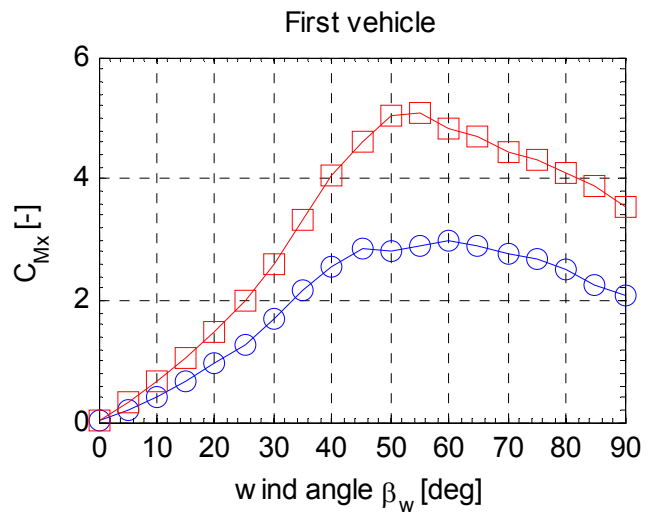

(c)

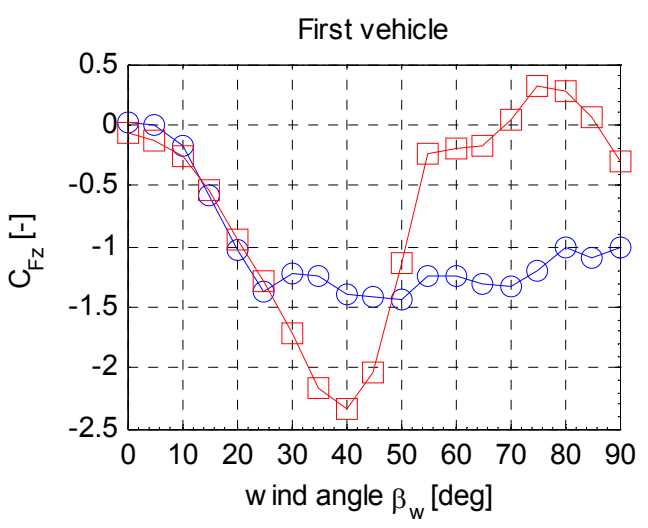

(b)

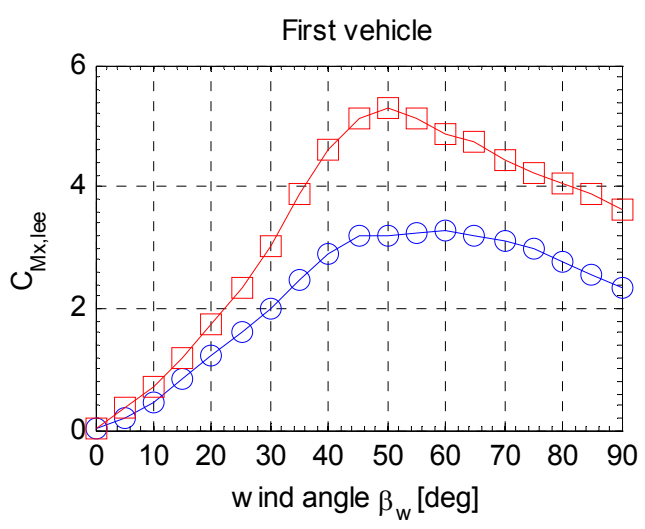

(d)

Figure 3: Comparison between force aerodynamic coefficients of train $\mathrm{A}$ and $\mathrm{B}$, first vehicle. $\mathrm{C}_{\mathrm{Fy}}(\mathrm{a}), \mathrm{C}_{\mathrm{Fz}}(\mathrm{b}), \mathrm{C}_{\mathrm{Mx}}(\mathrm{c})$ and $\mathrm{C}_{\mathrm{Mxlee}}(\mathrm{d})$.

Due to the coefficient definition, which uses a fixed value for parameters $A$ (equal to $10 \mathrm{~m}^{2}$ ) and $H$ (equal to $3 \mathrm{~m}$ ), the coefficients themselves represent normalized forces. In particular, the lateral force and the rolling moment linearly depend on the lateral area of the vehicle: considering that the ratio between the lateral areas of the two trains is equal to about 1.3 , it would be expected a similar ratio in terms of coefficients too. Nevertheless, the ratio between the $\mathrm{C}_{\mathrm{Fy}}$ coefficients of two considered trains is 1.3 up to about $40^{\circ}$ and then it increases up to 1.6. For $\mathrm{C}_{\mathrm{Mx}}$ 
instead, it is ranged in between 1.6-1.7, since low yaw angles. This means that the higher coefficients measured on train B are not due only to the bigger lateral area but also to its specific geometry: the main differences between the two trains are found in the nose, which however does not play an important role at high yaw angles, and in the upper part of the carbody. The more regular shape of the train B modifies the wake amplitude behind the train resulting in a modification of the lateral force and of the rolling moment.

Looking at Figure 3-b, we can see that the vertical force coefficient measured on the two vehicles is very different. Train A and train B show a similar trend up to $25^{\circ}$; over this angle, train A presents a constant coefficient up to $90^{\circ}$ while train $\mathrm{B}$ shows a negative peack value (at $40^{\circ}$ ) and then a sudden reduction up to zero. Obviously, this different behavior is due to the characteristic geometries of the two trains in both the upper and the lower part of the carbody.

In conclusion, the $\mathrm{C}_{\text {Mxlee }}$ coefficient shows the combined effect of the lateral and vertical forces in terms of overturning risk. The coefficients measured on the first vehicle of train $\mathrm{B}$ are significantly higher than the ones of train A: the ratio between the coefficients of the two trains is ranged between 1.4-1.6. By analysing this coefficient, the train B appears to be significantly more risky in terms of crosswind overturning. On the other hand, the overturning risk is influenced not only by the aerodynamic forces but also by the inertial-dynamic properties of the rail vehicle: to evaluate the actual overturning risk is necessary to calculate the Characteristic Wind Curves. For this reason, in the next section, the CWC of the two first vehicles will be evaluated and compared.

Figure 4 shows the same comparisons but for the second vehicles. Looking at lateral force and rolling moment coefficients (Figure 4-a, Figure 4-c and Figure 4-d) it is possible to draw the same observations: the ratio between the coefficients measured on train $\mathrm{B}$ and the corresponding ones of train $\mathrm{A}$ is much higher than 1.3 (1.4-1.7 for $\mathrm{C}_{\mathrm{Fy}}$, 1.6-1.8 for $\mathrm{C}_{\mathrm{Mx}}$ and 1.4-1.8 for $\mathrm{C}_{\mathrm{Mxlee}}$ ) and this is due to the specific geometries of the two vehicles, especially in the upper part of the carbody. On the contrary, on the second vehicle the two trains present a very similar trend of the vertical force coefficient.

In conclusion, also considering the second vehicle, the train $\mathrm{B}$ is more critical, in terms of overturning risk, than the train A; on the other hand, due to the fact that the second vehicle, thanks to its position in the convoy, is generally characterized by coefficients lower than that of the first one, the CWC have been evaluated only for the first vehicle of both the trains.

\section{CWC calculation}

The two trains have been compared also in terms of CWC. As described in EN 14067-6 [3], the most simple approach to calculate the CWC is the three mass model, based on the static equilibrium of all the acting forces and moments. In the following sections, a synthetic description of the approach is reported and then the CWCs evaluated for the first vehicles of the two considered trains are shown and commented. 


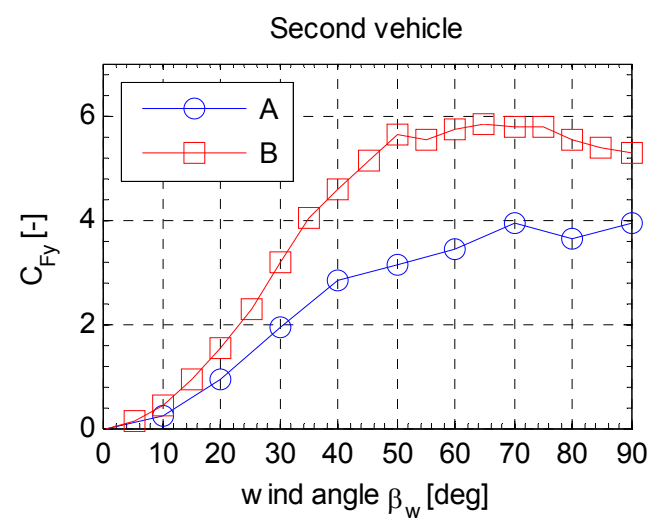

(a)

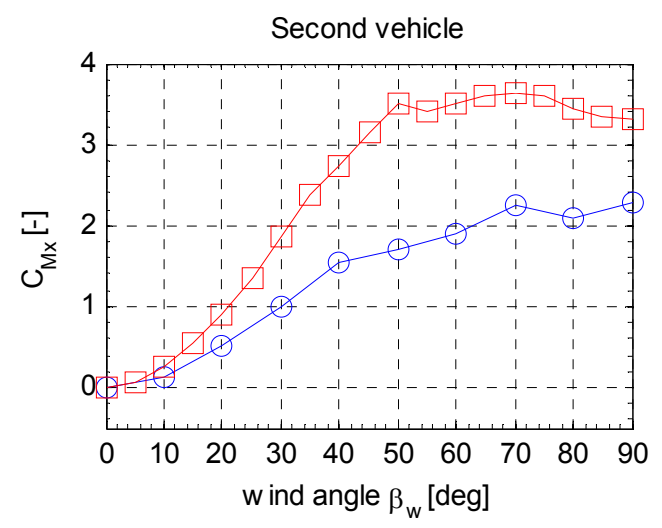

(c)

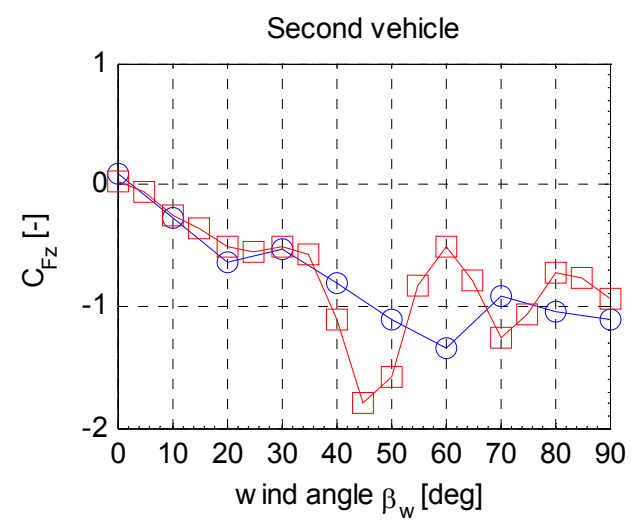

(b)

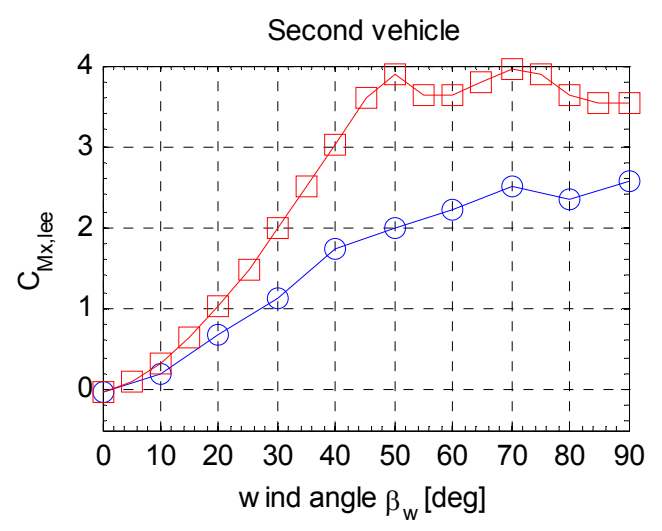

(d)

Figure 4: Comparison between force aerodynamic coefficients of train $\mathrm{A}$ and $\mathrm{B}$, second vehicle. $\mathrm{C}_{\mathrm{Fy}}(\mathrm{a}), \mathrm{C}_{\mathrm{Fz}}(\mathrm{b}), \mathrm{C}_{\mathrm{Mx}}(\mathrm{c})$ and $\mathrm{C}_{\text {Mxlee }}(\mathrm{d})$.

\subsection{Description of the three mass model}

According to the European standard EN 14067-6 [3] the cross wind stability of rolling stock is given by values of characteristic wind speeds that the rolling stock can withstand before exceeding some wheel unloading limit values. Various methods are available to determine the wheel unloading on passenger or freight vehicles due to cross wind. Sophisticated time-dependent multi-body simulation are often used to calculate the cross-wind stability ([8], [9] and [11]). Simpler method are also available like the "quasi-static three mass model" Even if this method is considered to be less precise it has been used in the present investigation for the comparison of the two vehicles due to its simplicity and the limited number of input data required.

Using this approach the calculation of the characteristic wind speed is based on the moment of equilibrium towards the leeward rail. The procedure relies on four fundamental quantities:

- the restoring moment $M_{m}$ due to the vehicle masses;

- the moment $M_{l a}$ due to the uncompensated lateral acceleration; 
- the moment $M_{C o G}$ due to the lateral movement of the centre of gravity of suspended masses (due to sway and lateral displacement);

- the aerodynamic moment $M_{x, \text { lee }}$ due to the wind load;

where the aerodynamic moment is calculated using the wind tunnel measured aerodynamic coefficients as:

$$
M_{x, l e e}(\beta)=\frac{1}{2} \rho V^{2} A h C_{M_{x, l e e}}(\beta)
$$

The vehicle is considered to consist of three principal masses: the unsprung mass, the primary sprung mass and the secondary sprung mass.

The equilibrium is:

$$
\sum M=f_{\Delta q} \frac{1}{f_{m}} M_{m}+M_{C o G}+M_{l a}-M_{x, l e e}=0
$$

where the factor $f_{\Delta q}$ describes the relative wheel unloading fixed to 0.9 and the method factor fm is fixed to 1.20. In this investigation the analysis is considered on a straightaway track and no lateral acceleration is considered.

We are aware that this simple assessment method has restrictions and, in particular, is not suitable for articulated vehicles like train A but it has been used in this comparative investigation for its simplicity and the results are not intended to be used for the cross-wind stability of the vehicles. In the future multi-body simulation will be performed and compared with the present results.

\subsection{CWC calculation}

Table 2 resumes the main inertial-dynamic properties of the two considered trains. Train A, being shorter, is obviously characterized by lower mass.

\begin{tabular}{ccc}
\hline Property & Train A & Train B \\
\hline Total mass $[\mathrm{kg}]$ & 21037 & 29240 \\
\hline Centre of gravity height $[\mathrm{m}]$ & 1.76 & 1.68 \\
\hline
\end{tabular}

Table 2: Inertial-dynamic properties of the two considered vehicles

Figure 5 shows the CWC evaluated for the two trains as a function of the absolute angle of wind with respect to the track, for two vehicle speeds: $V_{\text {train }}=60 \mathrm{~km} / \mathrm{h}$ and $\mathrm{V}_{\text {train }}=80 \mathrm{~km} / \mathrm{h}$. First of all, it is possible to see that, at all wind angles and for both the considered train velocities, the train $\mathrm{A}$, which has significantly lower aerodynamic coefficients, is characterized by a higher CWC than train B and, as a consequence, it is safer. Nevertheless, the differences between the CWCs are not constant: they reach a maximum around wind angle equal to $70^{\circ}$ but decrease going to $90^{\circ}$ and to $0^{\circ}$. Moreover, it is possible to observe that the lowest value of CWC in both the trains is reached not for perpendicular wind $\left(\beta_{\mathrm{w}}=90^{\circ}\right)$, but at $\beta_{\mathrm{w}}=70^{\circ}$. This is due to the typical trend of coefficients of first vehicles that show the maximum value for a wind angle significantly lower than $90^{\circ}$ (see Figure 3 ). 


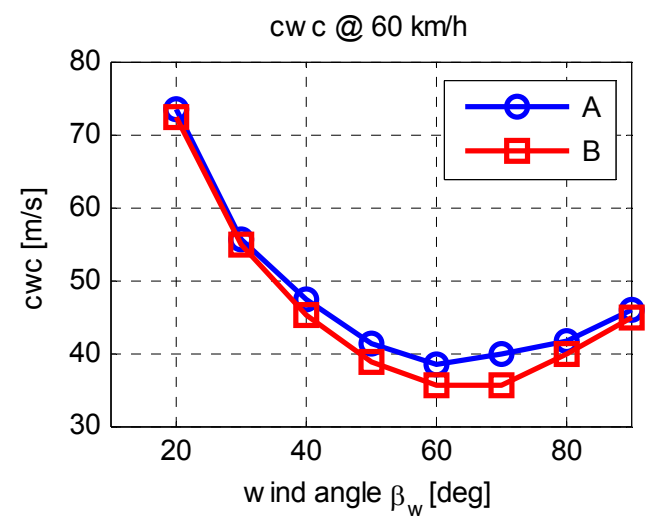

(a)

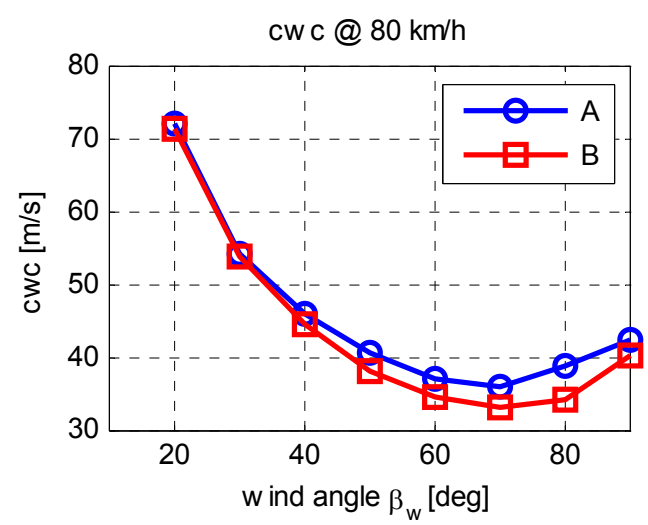

(b)

Figure 5: CWC for the two trains as a function of the wind angle (first vehicle only): $V_{\text {train }}=60 \mathrm{~km} / \mathrm{h}$ (a) and $\mathrm{V}_{\text {train }}=80 \mathrm{~km} / \mathrm{h}(\mathrm{b})$.

Analogous conclusions can be drawn from Figure 6 where, for the same two trains, the CWC as a function of the train speed for the two wind angles $\beta_{\mathrm{w}}=70^{\circ}$ and $\beta_{\mathrm{w}}=90^{\circ}$ are presented. Both the trains show lower values of $\mathrm{CWC}$ at $70^{\circ}$ of wind angle, on all the range of vehicle speed $30-120 \mathrm{~km} / \mathrm{h}$. Moreover, decreasing the train velocity, the differences between the two trains decrease, especially for $\beta_{\mathrm{w}}=90^{\circ}$.

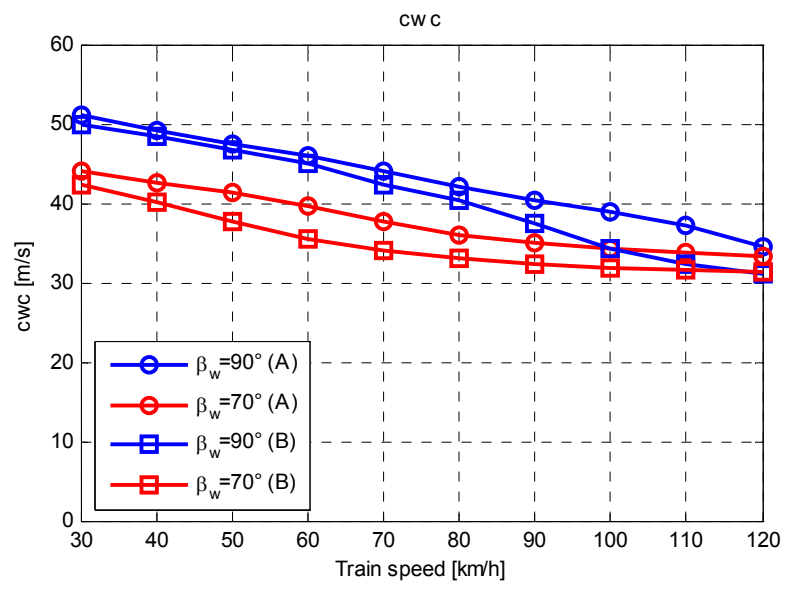

Figure 6: CWC for the two trains as a function of the wind speed (first vehicle only)

In conclusion, around a wind angle of $70^{\circ}$ and for high vehicle speeds, the aerodynamic loads $\left(\mathrm{M}_{\mathrm{x} \text {,lee }}\right.$ in eq. 3$)$ reach their maximum values: in this conditions, the train A, characterised by a lower mass but also by lower aerodynamic coefficients presents CWC significant higher than those calculated for train B. On the contrary, when the aerodynamic loads decrease with respect to the restoring weight forces $\left(\mathrm{M}_{\mathrm{m}}\right.$ in eq. 3$)$, the train $\mathrm{B}$, characterised by a more favourable mass distribution, is less penalised and the differences between CWC of the two vehicles significantly decrease. 


\section{Conclusions}

In this paper, the effects of cross wind on two different light-weight trains, characterised by different geometries and lengths and by different mass distribution, have been investigated. In order to compare the two trains in terms of response to cross wind, two subsequent analyses have been performed:

- wind tunnel experimental tests on scale vehicles to measure the force and moment aerodynamic coefficients;

- Characteristic Wind Curves of the first vehicle of the two trains through a simplified numerical procedure, to evaluate of the rollover risk.

From the wind tunnel tests we found that the longest train presents the larger aerodynamic coefficients. However, the differences on the lateral force and rolling moment coefficient are not due only to variations in the lateral area but also to the different geometry of the two trains, especially in the upper part of the carbody. Finally, the analysis of the calculated CWC have shown that the train A, characterised by lower aerodynamic coefficients, has a higher $\mathrm{CWC}$ at all wind angles and vehicle speeds. On the other hand, considering that train A, being shorter, is lighter and, in general, it is characterised by a less favourable mass distribution, the differences between the CWCs of the two trains are more important when the aerodynamic loads (Mx,lee in eq. 3) are greater (around wind angle of $70^{\circ}$ and for vehicle speeds higher and higher). On the contrary, when the aerodynamic loads decrease with respect to the restoring weight forces (Mm in eq. 3), differences between CWC of the two vehicles decrease.

\section{References}

[1] Baker, C.J., 1991a. Ground vehicles in high cross winds part 1: steady aerodynamic forces. Journal of Fluids and Structures 5, 69-90.

[2] Baker, C., Cheli, F., Orellano, A., Paradot, N., Proppe, C. \& Rocchi, D. 2009. Cross-wind effects on road and rail vehicles. Vehicle System Dynamics, vol. 47, no. 8, pp. 983-1022.

[3] CEN 2010, EN14067-6. Railway applications - Aerodynamics. - Part 6: Cross wind. CEN, Brussels.

[4] TSI 2008, European Rail Agency. Technical Specification for Interoperability (TSI 232/2008) - Rolling Stock subsystem, 96/48/EC

[5] Bocciolone M., Cheli F., Corradi R., Muggiasca S., Tomasini G., 2008. Crosswind action on rail vehicles: wind tunnel experimental analyses. Journal of Wind Engineering and Indus-trial Aerodynamics, 96, 584-610

[6] Cheli, F., Corradi R., Rocchi D., Tomasini G., Maestrini E., 2010. Wind tunnel tests on train scale models to investigate the effect of infrastructure scenario, Journal of Wind Engineering and Industrial Aerodynamics, 98 , 353362.

[7] Baker, C.J. 1991c. Ground vehicles in high cross winds Part 3. The interaction of aerodynamic forces and the vehicle system. Journal of Fluids \& Structures $5,221-241$ 
[8] Cheli, P. Belforte, S. Melzi, E. Sabbioni, G. Tomasini, 2006. A numericalexperimental ap-proach for evaluating cross wind aerodynamic effects on heavy vehicles. Journal of Vehicle System Dynamics Supplement, 44, 791804.

[9] Cheli, F., Corradi, R., Tomasini, G., 2012. Crosswind action on rail vehicles: A methodology for the estimation of the characteristic wind curves, J. Wind Eng. Ind. Aerodyn. 104-106 248-255.

[10] F. Cheli, R. Corradi ,G. Diana, F. Ripamonti , D. Rocchi, G. Tomasini, 2007. Methodologies for assessing trains CWC through time-domain multibody simulations, 12th ICWE International Conference on Wind Engineering, Cairns, Queensland, AUSTRALIA, JULY 1 - 62007

[11] Baker C.J. 2010. The simulation of unsteady aerodynamic cross wind forces on trains. J. Wind Eng. Ind. Aerodyn. 98 (2010) 88-99 